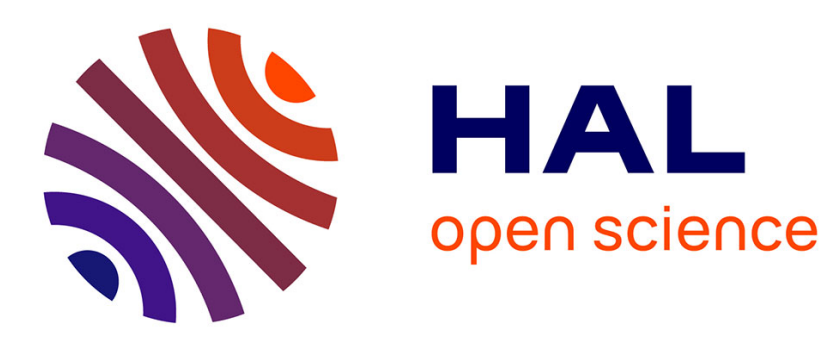

\title{
Recent advances in understanding the capacitive storage in microporous carbons
}

\author{
Barbara Daffos, Pierre-Louis Taberna, Yury Gogotsi, Patrice Simon
}

\section{To cite this version:}

Barbara Daffos, Pierre-Louis Taberna, Yury Gogotsi, Patrice Simon. Recent advances in understanding the capacitive storage in microporous carbons. Fuel Cells, 2010, 10 (5), pp.819. 10.1002/fuce.200900192 . hal-00552370

\section{HAL Id: hal-00552370 \\ https://hal.science/hal-00552370}

Submitted on 6 Jan 2011

HAL is a multi-disciplinary open access archive for the deposit and dissemination of scientific research documents, whether they are published or not. The documents may come from teaching and research institutions in France or abroad, or from public or private research centers.
L'archive ouverte pluridisciplinaire HAL, est destinée au dépôt et à la diffusion de documents scientifiques de niveau recherche, publiés ou non, émanant des établissements d'enseignement et de recherche français ou étrangers, des laboratoires publics ou privés. 


\section{Recent advances in understanding the capacitive storage in microporous carbons}

\begin{tabular}{|c|c|}
\hline Journal: & Fuel Cells \\
\hline Manuscript ID: & fuce.200900192.R3 \\
\hline Wiley - Manuscript type: & Review \\
\hline $\begin{array}{r}\text { Date Submitted by the } \\
\text { Author: }\end{array}$ & 29-Jan-2010 \\
\hline Complete List of Authors: & $\begin{array}{l}\text { DAFFOS, Barbara; Université Paul Sabatier, CIRIMAT } \\
\text { TABERNA, Pierre-Louis; Université Paul Sabatier, CIRIMAT } \\
\text { GOGOTSI, Yury; Drexel University, Department of Materials Science } \\
\text { and Engineering and A.J. Drexel Nanotechnology Institute } \\
\text { SIMON, Patrice; Universté Paul Sabatier, CIRIMAT }\end{array}$ \\
\hline Keywords: & $\begin{array}{l}\text { Electrical Storage Systems, Electrochemical, Electrochemical Power } \\
\text { Sources, Electrochemical Impedance Spectroscopy, Mass Transport }\end{array}$ \\
\hline
\end{tabular}

\section{scholarONE" \\ Manuscript Central}




\title{
Recent advances in understanding the capacitive storage in microporous carbons
}

\author{
B. Daffos, ${ }^{1}$ P.-L. Taberna, ${ }^{1}$ Y. Gogotsi ${ }^{2}$ and P. Simon ${ }^{1, *}$ \\ ${ }^{1}$ Université de Toulouse, CIRIMAT, UMR-CNRS 5085, 31062 Toulouse Cedex 4, France \\ ${ }^{2}$ Department of Materials Science and Engineering and A.J. Drexel Nanotechnology Institute, Drexel \\ University, Philadelphia, PA 19104, USA \\ * Corresponding author
}

\begin{abstract}
This article presents a review of our recent work on capacitance of carbide-derived carbons. Specific capacitance as high as $14 \mu \mathrm{F} / \mathrm{cm}^{2}$ or $160 \mathrm{~F} / \mathrm{g}$ was achieved using carbide-derived carbons with tailored subnanometer pore size, which is significantly higher than $6 \mu \mathrm{F} / \mathrm{cm}^{2}$ or $100 \mathrm{~F} / \mathrm{g}$ ) for conventional activated carbons. Such high capacitance was obtained in several types of organic electrolytes with or without solvent. A maximum is obtained for the carbons with the mean pore size close to the bare ion size, ruling out the traditional point of view that mesoporosity is highly required for maximum capacitance. Surprisingly, carbons with subnanometer porosity exhibit high capacitance retention, since only a $10 \%$ loss is measured when $6 \mathrm{~A} / \mathrm{g}$ discharge is drawn. These findings show the importance of fitting the ion size with the mean pore size. The double layer theory falls short to explain such charge storage mechanisms at the nanometer scale, thus atomistic modeling is required to find out an alternative charge storage model.
\end{abstract}




\section{Introduction}

Electrical Double Layer Capacitors (EDLCs), also known as supercapacitors, are one of the most promising electrochemical energy storage devices for high power delivery or energy harvesting applications (1-3). EDLCs charge storage mechanism is electrostatic by nature, and requires storage of opposite charges at the two electrodes, properly balanced by the ions from the electrolyte. This is achieved through the reversible adsorption of ions from an electrolyte onto high surface area carbons.

Differentiating from batteries or pseudocapacitors $(1,3)$, there is no redox reaction involved in the charge storage mechanism and the charge is stored at the surface of the carbon materials. Accordingly, it can be quickly released or captured and this explains the high power capability of EDLCs. As a drawback, the amount of charge stored at the surface is limited and the energy density of the EDLCs will always be about an order of magnitude lower than that of batteries. EDLCs are already used in many commercial applications such as power electronics, aircrafts, cranes, elevators, tramways and others (3). One of the most promising applications are the Hybrid Vehicles (HVs) in combination with Internal Combustion Engines, and the Electric Vehicles (HEVs) where EDLCs could be combined with a battery pack for braking energy recovery or short-time acceleration power. For a fuelcell powered HEV, the use of EDLCs would be of great interest for power delivery during the first seconds the fuel cell needs to reach operational state.

Today, the energy density achieved by commercial products (about $5 \mathrm{Wh} \cdot \mathrm{kg}^{-1}$ ) limits their use to few seconds of charge/discharge, which is sufficient for energy harvesting (recovery of potential energy in cranes and elevators, braking energy in tramways and HEVs or mechanical energy coupled with MEMS) (3). However, increase of the operation time up to $10 \mathrm{~s}$ or more would definitely secure a place for supercapacitors at the forefront of the energy 
storage harvesting devices. Therefore improving the energy density of supercapacitors would enable many new applications.

Being proportional to the voltage square, both power and energy are increased when the cell voltage is increased as shown in equations (1) and (2) below:

$$
\begin{aligned}
& E=\frac{1}{2} C \times V^{2} \\
& P=\frac{V^{2}}{4 R}
\end{aligned}
$$

where $V$ is the cell voltage $(\mathrm{V}), E$ is the energy $(\mathrm{J}), C$ is the capacitance $(\mathrm{F}), P$ is the power $(\mathrm{W})$ and $R$ is the series resistance $(\Omega)$.

Therefore, much effort focused on the increase of the operating voltage of supercapacitors by designing new electrolytes (4)(5). One strategy today is the use of ionic liquids as electrolytes $(6)(7)(8)(9)$, which can ensure a high cell voltage (up to $4 \mathrm{~V})$, despite a low ionic conductivity.

Combining a faradic electrode with an EDLC electrode is another way to improve the energy density. Such systems, named Hybrid Capacitors, reach high energy densities of more than 15 Wh. $\mathrm{kg}^{-1}$ for the Li-ion capacitor operating in organic electrolyte with a pre-lithiated graphite negative electrode (10). The combination of a negative carbon electrode to a $\mathrm{MnO}_{2}$ $(11)(12)(13)(14), \mathrm{NiOOH}(15)(16)$ or $\mathrm{PbO}_{2}(17)(18)$ positive electrodes leads to high power hybrid systems operating in aqueous electrolytes.

However, whatever hybrid systems are being considered, they still suffer from the drawbacks linked to the faradic electrode, which are a limited cyclability for high depth of discharge ( $>$ $70 \%$ ) or high rate of charge (19). Another route to increase the energy density of 
supercapacitors, is to keep the symmetric EDLC carbon/carbon system and increase the capacitance of these porous carbons. This solution may appear as more complex, since there is less flexibility on the choice of the materials, but the supercapacitor cyclability, power performance and low temperature behaviors are preserved (3). In this paper, we will try to give an update on the most recent work relating to the design of microporous carbons for EDLC applications.

\section{Discussion}

\subsection{Capacitance vs pore size in organic electrolytes}

EDLCs are electrochemical capacitors that store the charge electrostatically using reversible adsorption of ions of the electrolyte onto active materials that are electrochemically stable and have high accessible SSA. Charge separation occurs on polarization at the electrodeelectrolyte interface, producing what Helmholtz (21) described in 1853 as the double layer capacitance $(20,22) C$

$$
C=\frac{\varepsilon A}{d} \quad
$$

where $\varepsilon$ is the electrolyte dielectric constant, $A$ - the surface area accessible to ions and $d$ - the distance between the centre of the ion and the carbon surface. EDLCs use high specific surface area (SSA) carbons to increase the total available surface area for ion adsorption. Such carbons are traditionally obtained from carbon-rich organic precursors by heat treatment in inert atmosphere (carbonisation process). High surface area is achieved through what is called the "activation" consisting in a partial, controlled oxidation of the carbon precursor (23). SSA as high as $1,500-2,600 \mathrm{~m}^{2} \cdot \mathrm{g}^{-1}$ can be achieved by activation. 
The specific capacitance of carbons expressed in Farads per gram of carbon (F.g $\left.\mathrm{g}^{-1}\right)$ shows a linear dependence on surface area up to $1500 \mathrm{~m}^{2} \cdot \mathrm{g}^{-1}$, but tends rapidly to plateau when SSA is further increased (24). As a consequence, the way in which the surface is developed has a great impact on the value of specific capacitance achieved. One of the key issues in designing nanostructured carbons for EDLC applications is then the understanding of the relationship between the electrolyte ion size and the carbon pore size (25)(26). Because of the mean size of the solvated ions in non-aqueous electrolytes (about $1 \mathrm{~nm})(27)$, a mean carbon pore size of about 2-3 nm was thought to be the best compromise to reach high capacitance values. Indeed, such pore size was large enough to host adsorbed ions on both sides of the carbon pore walls but small enough to minimize the voids and maximize the energy density (Fig. 1). However, all attempts to prepare carbons using standard activation or template-based synthesis failed to significantly increase the carbon capacitance (3). At the same time, some authors mentioned that surprisingly high capacitance could be obtained with microporous carbons, and this suggested that even the small micropores (size less than $2 \mathrm{~nm}$ ) could contribute to the charge storage $(26)(28)(29)$.

Charge storage in pores smaller than the size of solvated ions of the electrolyte has been recently demonstrated by using Carbide Derived Carbons (CDCs) (30). CDCs were obtained by chlorination of a metal carbide ( $\mathrm{TiC}$ in our case) according to

$$
\mathrm{TiC}+2 \mathrm{Cl}_{2} \rightarrow \mathrm{TiCl}_{4}+\mathrm{C}
$$

Using this synthesis process, it is possible to prepare carbons with a fine-tuned and a narrow pore size distribution, which is definitely not possible through the standard activation process (23). CDCs with controlled pore size from 0.6 to $1 \mathrm{~nm}$ were prepared and electrochemically tested in a $1.5 \mathrm{M} \mathrm{NEt}_{4} \mathrm{BF}_{4}$ in acetonitrile electrolyte. 
Figure 1 shows the change of the normalized capacitance vs the carbon pore size; normalized capacitance $\left(\mu \mathrm{F} . \mathrm{cm}^{-2}\right)$ was obtained by dividing the gravimetric capacitance by the SSA. Some data from the literature obtained with mesoporous carbons reported in Figure 1 follows the expected traditional behavior: when the carbon pore size decreases in the mesoporous range (down to $2 \mathrm{~nm}$ ), the normalized capacitance decreases. However, the results obtained with the CDCs in the $0.6-1 \mathrm{~nm}$ pore range show a sharp capacitance increase following a power law dependence with $r_{\text {pore }}{ }^{-1}$. This was the first demonstration of the anomalous capacitance increase observed with microporous carbons with controlled, narrow pore size distribution. Such micropores, smaller than the size of the solvated $\mathrm{NEt}_{4}{ }^{+}$and $\mathrm{BF}_{4}^{-}$ions in acetonitrile $(27,30)$, were thus accessible to the ions of the electrolyte. The proposed hypothesis was that these narrow pores were accessible thanks to a partial desolvation of the ions. A smaller approaching distance (d) of the ion to the carbon surface was responsible for the capacitance increase according to equation (3).

Several recent studies confirmed these results. Kaneko's group observed with carbon nanohorns that ions were able to pass through gates smaller than the size of the solvated ions in propylene carbonate-based electrolytes (27). Meunier's group proposed a mathematical fit of the anomalous capacitance increase in these micropores based on the Electrical Wire-inCylinder model (EWC) capacitance equation $(31,32)$. Thanks to this model, it was possible to calculate an average size of the ions inside the pores, which was found to be smaller than the bare ion size.

Surprisingly, the power capability of laboratory EDLC devices assembled with CDCs powders was not deeply affected by the use of microporous carbons. Figure 2a shows a Nyquist plot for different CDC samples $(0.72-1.1 \mathrm{~nm})$. AC Series resistance (measured at 
high frequency) as low as $0.5 \mathrm{Ohm} . \mathrm{cm}^{2}$ was obtained in $1.5 \mathrm{M} \mathrm{NEt}_{4} \mathrm{BF}_{4}$ in an acetonitrile electrolyte. At low frequencies, where the ionic resistance of the electrolyte inside the porous network can be seen, the DC resistances were in the range of 2-3 $\mathrm{Ohm}_{\mathrm{cm}}{ }^{2}$, i.e. in the same range as for activated carbon-based electrodes (33). The capacitance increase using these microporous carbons was not achieved at the expense of the power performance since these series resistance values are similar to that of standard activated carbons (33). Figure $2 \mathrm{~b}$ shows the capacitance change vs the current density. The capacitance retention was found to be very good, with only a $10 \%$ loss for the best sample $(0.72 \mathrm{~nm})$ when the current was increased up to $6 \mathrm{~A}^{-1}{ }^{-1}$. The power capability of the CDCs was very good when the pore size was well adapted to the ion size, between 0.72 and $0.76 \mathrm{~nm}$. Thus, it is possible to reach high energy and high power density with sub-nanometer microporous carbons.

Using the Cavity Micro Electrode technique (CME) developed by Cachet-Vivier et al. (34), we have studied the electrochemical behavior of the $\mathrm{CDCs}$ in $\mathrm{NEt}_{4} \mathrm{BF}_{4}$ in acetonitrile electrolyte (35). The CME allowed the recording of electrochemical behavior of active material eliminating effects of separators, current collectors and other device components. Figure 3 shows the CVs of four CDC samples recorded at $100 \mathrm{mV} \cdot \mathrm{s}^{-1}$ in $1.5 \mathrm{M} \mathrm{NEt}_{4} \mathrm{BF}_{4}$ in $\mathrm{AN}$ electrolyte between-1.3 V/Ref. and $+1 \mathrm{~V} /$ Ref. All the plots were normalized to the maximum capacitive current at $1 \mathrm{~V} /$ ref.. The capacitive behavior originates from the $\mathrm{NEt}_{4}{ }^{+}$cation adsorption negative of the $\mathrm{OCV}$, which was measured close to $0 \mathrm{~V} / \mathrm{Ref}$ for all samples. For potential higher than $\mathrm{OCV}$, the $\mathrm{BF}_{4}^{-}$anions adsorption can be seen. In this potential range ( potentials higher than OCV), the CVs are rectangular-shaped - typical for pure double-layer capacitive behavior. When the potential scan is reversed at $1 \mathrm{~V} / \mathrm{Ref}$ to negative, only slight changes in the CVs can be observed above the OCV. This potential range corresponds to the discharge of the positive electrode, where anions are removed from the porous carbons. When 
the potential scan was negative of the OCV $(0 \mathrm{~V} / \mathrm{Ref})$, the rectangular shape of the CV was lost for all samples except the one with the largest pore size $(1 \mathrm{~nm})$. The smaller the pore size (the lower the synthesis temperature), the more distorted the CVs. This shift from purely capacitive behavior is also present when the potential scan rate is reversed at $-1.3 \mathrm{~V} / \mathrm{Ref}$ to positive values. These distortions of CVs were also reported by Salitra et al. (26) using a conventional 3-electrode cell with an activated carbon cloth as the active material. They were linked with the limitation in the pore accessibility because of the well-known "sieving effect" $(26,36)$ hampering the ion transport inside the small, narrow pores.

From these measurements, it was deduced that anion adsorptions could occur without any limitation even for pore size of $0.68 \mathrm{~nm}$ (rectangular shape of the CVs), that meant that the effective anion size seen by the carbon during the adsorption was $\leq 0.68 \mathrm{~nm}$. In the same way, the effective size of the adsorbed cation in AN during double layer charging/discharging can be estimated between $0.76 \mathrm{~nm}$ and $1 \mathrm{~nm}$, since $\mathrm{CV}$ distortions were observed for pore size less than $0.76 \mathrm{~nm}$. Comparing these effective ion size to the solvated ion size $(1.3 \mathrm{~nm}$ and $1.16 \mathrm{~nm}$ for the cation and the anion respectively), it appears obvious that the ions need to be, at least, partially desolvated to enter the micropores smaller than $1 \mathrm{~nm}$, thus confirming the previous results. Recent results reported by Mysyk et al. (37) confirmed this sieving effect. However, in this recent paper, only 2-electrode measurements were made and it was not possible to distinguish between anion and cation contributions to the capacitive process.

\subsection{Capacitance vs pore size in solvent-free electrolytes}

In a solvent-based electrolyte, the determination of the exact solvation shell is sometimes difficult, depending if one considers the first, second or subsequent solvation sphere. The next step has thus been to try to get free from the ion solvation shell, by using an ionic liquid 
electrolyte. The electrochemical characterization of CDC electrodes was conducted at $60^{\circ} \mathrm{C}$ in Ethyl-MethylImmidazolium-TriFluoro-methane-SulfonylImide ionic liquid (EMI-TFSI), according to two main criteria (38). First, the ionic conductivity of the EMI-TFSI neat electrolyte at $60^{\circ} \mathrm{C}$ is about $15 \mathrm{mS} . \mathrm{cm}^{-1}$ which allows the ohmic drop to remain at a reasonable value during electrochemical measurements. Additionally, the ion sizes were calculated as $0.79 \mathrm{~nm}$ and $0.76 \mathrm{~nm}$ respectively for TFSI and EMI ions, meaning that ion sizes were i) very close were and ii) in the range of the CDC pore size (38). Figure 4 shows the change of the gravimetric capacitance (a) and normalized capacitance (b) vs the carbon pore size for the cell, the positive and the negative electrodes (38). The normalized capacitance was obtained by dividing the gravimetric capacitance $\left(\mathrm{F} \cdot \mathrm{g}^{-1}\right)$ by the SSA $\left(\mathrm{m}^{2} \cdot \mathrm{g}^{-1}\right)$.

In Figure 4 , the electrode specific capacitance $\left(\mathrm{C}^{\prime}\right.$ electrode $)$ is calculated from the weight of the carbon in one electrode $\left(\mathrm{m}_{\text {carbon }}\right)$ according to equation (3):

$$
C_{\text {electrode }\left(F \cdot g^{-1}\right)}^{\prime}=\frac{C_{\text {electrode }}}{m_{\text {carbon }}}
$$

The calculated electrode capacitance (C"electrode) was calculated from the 2-electrode cell capacitance $\mathrm{C}_{\text {cell }}$ according to equation (4):

$$
C_{\text {electrode }\left(F . g^{-1}\right)}^{\prime \prime}=\frac{2 \times C_{\text {cell }}}{m_{\text {carbon }}}
$$

From Figures $4 \mathrm{a}$ and $4 \mathrm{~b}$, it can be seen that positive, negative and cell capacitance show a maximum at the same pore size. This is consistent with the similar ion sizes observed for the $\mathrm{EMI}^{+}$and TFSI. More surprising is that the maximum capacitance was obtained for pore size close to the ion size, $0.72 \mathrm{~nm}$. These results rules out the way charge storage is traditionally described in EDLC materials, with ions adsorbed on both pore walls: carbon pore size is here 
in the same range as the ion size and there is no space available for more than one ion per pore. However, the maximum capacitance at $0.72 \mathrm{~nm}$ agrees well with the ion size, taking into account the asymmetry of the ions and accuracy of pore size measurements. At this point, pore size is perfectly adapted to the ion size and ion adsorption is achieved in an efficient way. Both, larger and smaller pores show a significant drop in capacitance. When pore size is increased, average distance between pore wall and the centre of the ion (d) is increased and then the capacitance for pores larger than around $0.72 \mathrm{~nm}$ decreases according to equation (3). For smaller pore size, the steric effect limit the ion accessibility and the capacitance is decreased.

Additionally, a commercial microporous activated carbon tested in the same conditions gave a capacitance of about $100 \mathrm{~F}^{-1} \mathrm{~g}^{-1}$ and $6 \mu \mathrm{F} . \mathrm{cm}^{-2}$. When compared to the maximum capacitance values reported in Figure 4, it can be seen that matching the pore size close to the ion size leads to a $60 \%$ capacitance increase. There is no evidence of any charge saturation like recently reported $(37,39)$; moreover, the opposite effect was observed. This work suggests a general approach to selecting a porous electrode / electrolyte couple in order to maximize the capacitance, which has been now proved for both, organic salt in a solvent and solvent-free liquid electrolytes. More basic work is needed to understand the mechanism of this capacitance increase. In this aim, modeling of ions and their environment when adsorbed inside these narrow subnanometer pores is needed. As an example, Yang et al. (40) recently used the molecular simulation to model the electrical double layer capacitance using carbon nanotubes. These simulations confirmed an increase of the capacitance when decreasing the pore size in the microporous range. Combining in-situ experimental measurements to mathematical modeling will be of great help in the understanding of the mechanism of anomalous capacitance increase when carbon pore size matches the ion size. This will affect 


\section{Acknowledgements}

Work at Paul Sabatier University was supported by Délégation Générale pour l'Armement. Y.G. thanks the US Department of Energy for financial support. Collaboration between the participating universities was supported by a Partnership University Fund (PUF) grant.

\section{References}

1. B. E. Conway, Electrochemical Supercapacitors: Scientific Fundamentals and Technological Applications (Kluwer, 1999), pp.

2. R. Kotz, M. Carlen, Electrochimica Acta 45, 2483 (2000).

3. P. Simon, Y. Gogotsi, Nature Materials 7, 845 (Nov, 2008).

4. A. Janes, E. Lust, Journal Of Electroanalytical Chemistry 588, 285 (Mar 15, 2006).

5. P. Staiti, F. Lufrano, Journal Of The Electrochemical Society 152, A617 (2005).

6. M. Armand, F. Endres, D. R. MacFarlane, H. Ohno, B. Scrosati, Nature Materials 8, 621 (Aug, 2009).

7. M. Lazzari, F. Soavi, M. Mastragostino, Journal Of The Electrochemical Society 156, A661 (2009). 
8. A. Balducci, F. Soavi, M. Mastragostino, Applied Physics A-Materials Science \& Processing 82, 627 (Mar, 2006).

9. C. Arbizzani, S. Beninati, M. Lazzari, F. Soavi, M. Mastragostino, Journal Of Power Sources 174, 648 (Dec 6, 2007).

10. e. a. H. Gualous, Proceedings of the ESSCAP 2008 conference, Roma, Italy, November 6-8 2008 (2008).

11. C. C. Hu, T. W. Tsou, Electrochemistry Communications 4, 105 (Feb, 2002).

12. Y. K. Zhou, M. Toupin, D. Belanger, T. Brousse, F. Favier, Journal Of Physics And Chemistry Of Solids 67, 1351 (May-Jun, 2006).

13. T. Cottineau, M. Toupin, T. Delahaye, T. Brousse and D. Belanger, Applied Phys. A, Materials Science and processing 82 (2006) 599-606.

14. T. Brousse et al., Journal Of Power Sources 173, 633 (Nov 8, 2007).

15. http://www.esma-cap.com/.

16. http://www.elit-cap.com/, (2008).

17. L. T. Lam et al., Journal Of Power Sources 174, 16 (Nov 22, 2007).

18. P. Perret, T. Brousse, D. Belanger, D. Guay, Journal Of The Electrochemical Society 156, A645 (2009).

19. J. Miller, A. F. Burke, The Electrochemical Society Interface 17 (2008) 53.

20. G. Gouy, Compt. Rend. 149, 654 (1910).

21. H. V. Helmholtz, Ann. Phys. 29, 337 (1879).

22. O. Stern, Z. Elektrochem. 30, 508 (1924).

23. A. G. Pandolfo, A. F. Hollenkamp, Journal Of Power Sources 157, 11 (Jun 19, 2006).

24. O. Barbieri, M. Hahn, A. Herzog, R. Kotz, Carbon 43, 1303 (2005).

25. M. Endo et al., Journal Of The Electrochemical Society 148, A910 (2001).

26. G. Salitra, A. Soffer, L. Eliad, Y. Cohen, D. Aurback, Journal Of The Electrochemical Society 147, 2486 (2000).

27. C. M. Yang et al., Journal Of The American Chemical Society 129, 20 (Jan 10, 2007).

28. C. Vix-Guterl et al., Carbon 43, 1293 (May, 2005).

29. A. Janes, L. Permann, P. Nigu, E. Lust, Surface Science 560, 145 (2004).

30. J. Chmiola et al., Science 313, 1760 (2006).

31. J. S. Huang, B. G. Sumpter, V. Meunier, Chemistry-A European Journal 14, 6614 (2008).

32. J. S. Huang, B. G. Sumpter, V. Meunier, Angewandte Chemie-International Edition 47, 520 (2008).

33. C. Portet, P. L. Taberna, P. Simon, C. Laberty-Robert, Electrochimica Acta 49, 905 (Mar 1, 2004).

34. C. Cachet-Vivier, V. Vivier, C. S. Cha, J. Y. Nedelec, L. T. Yu, Electrochimica Acta 47, 181 (Sep 1, 2001).

35. R. Lin, Taberna, P.L., Chmiola, J., Guay, D., Gogotsi, Y. and P. Simon, Journal Of The Electrochemical Society 156, A7 (2009).

36. D. Aurbach et al., Journal Of The Electrochemical Society 155, A745 (2008).

37. R. Mysyk, E. Raymundo-Pinero, F. Beguin, Electrochemistry Communications 11, 554 (Mar, 2009).

38. C. Largeot et al., Journal Of The American Chemical Society 130, 2730 (2008).

39. C. O. Ania, J. Pernak, F. Stefaniak, E. Raymundo-Pinero, F. Beguin, Carbon 47, 3158 (Nov, 2009).

40. L. Yang, B. H. Fishbine, A. Migliori, L. R. Pratt, Journal Of The American Chemical Society 131, 12373 (Sep 2, 2009). 


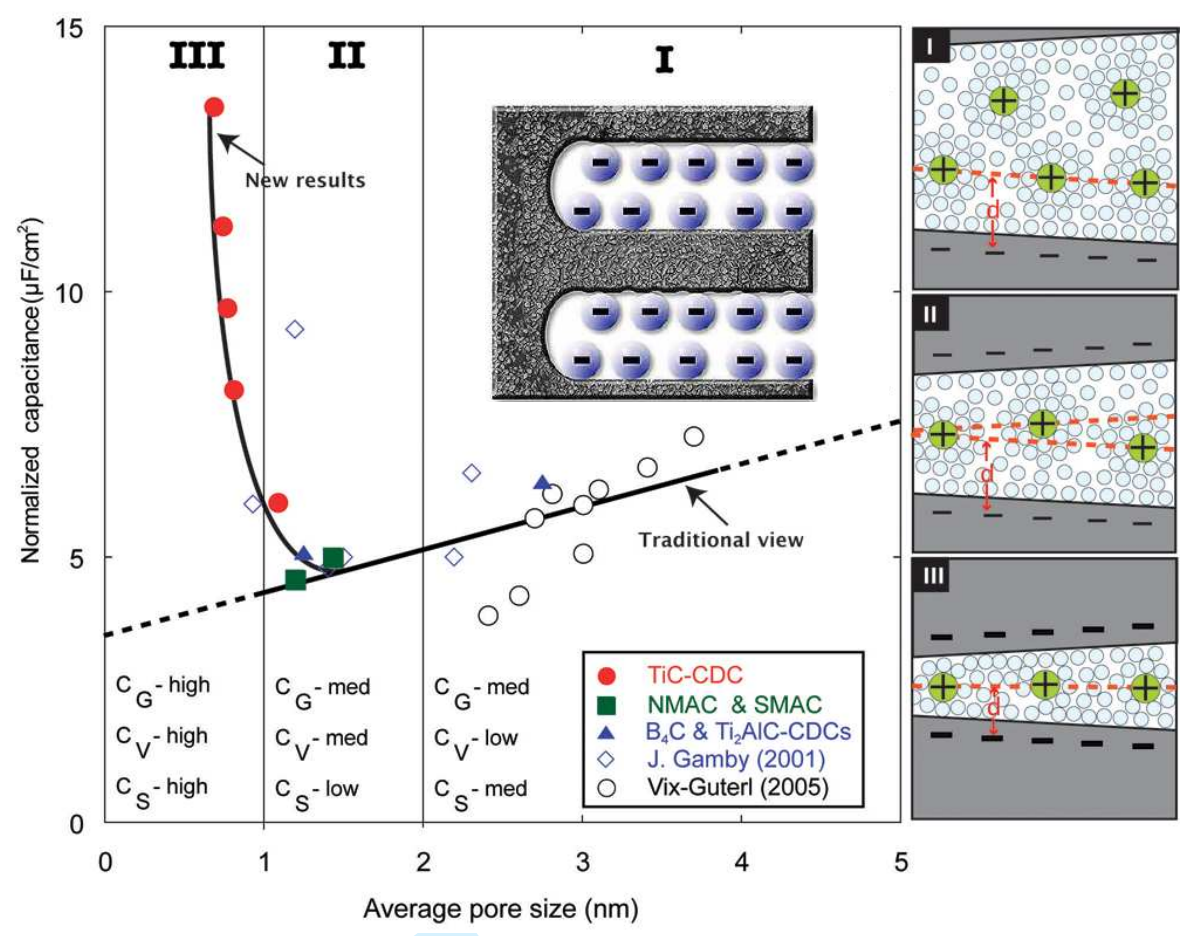

Figure 1:

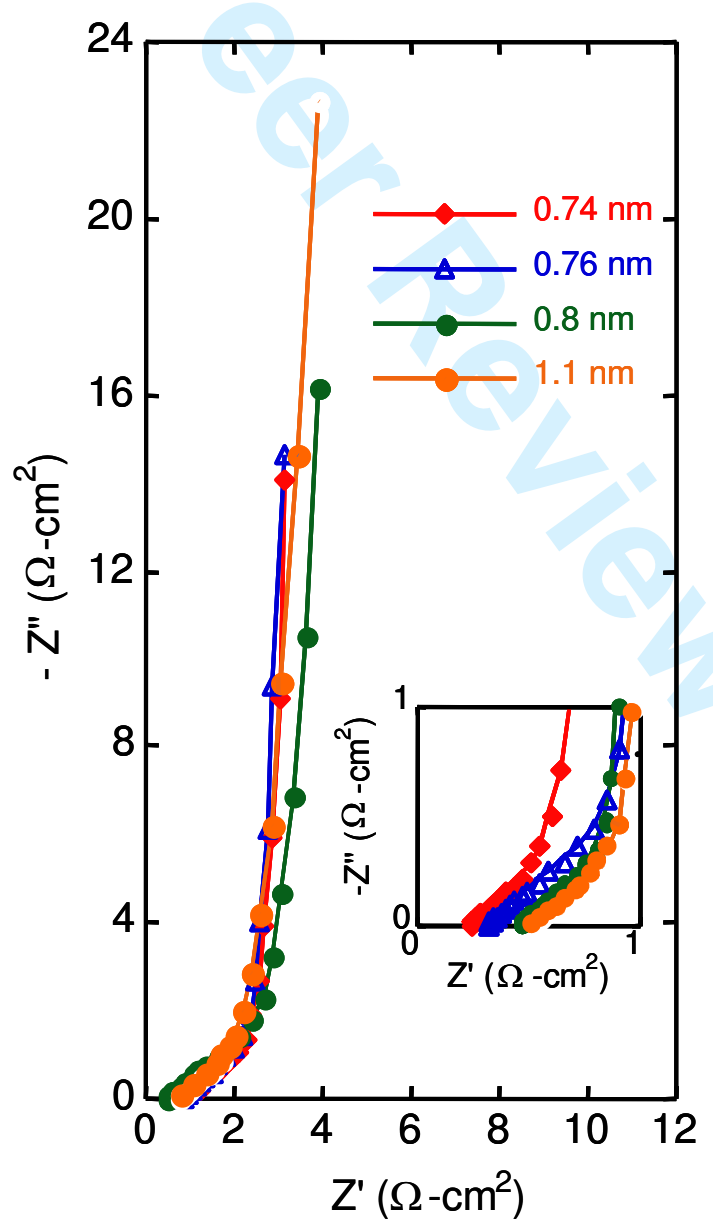

Figure 2a: 
Figure 2b:
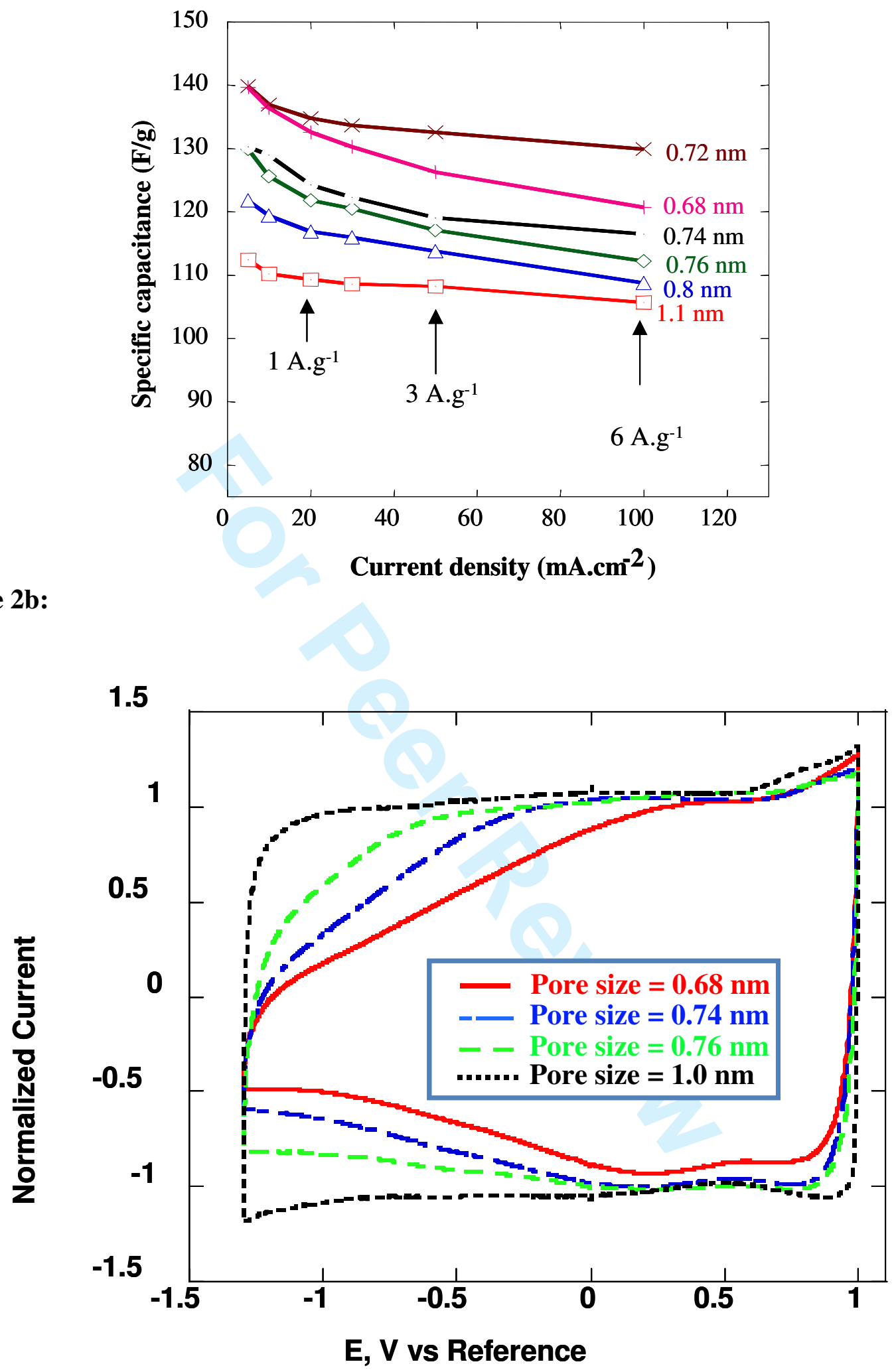

Figure 3: 

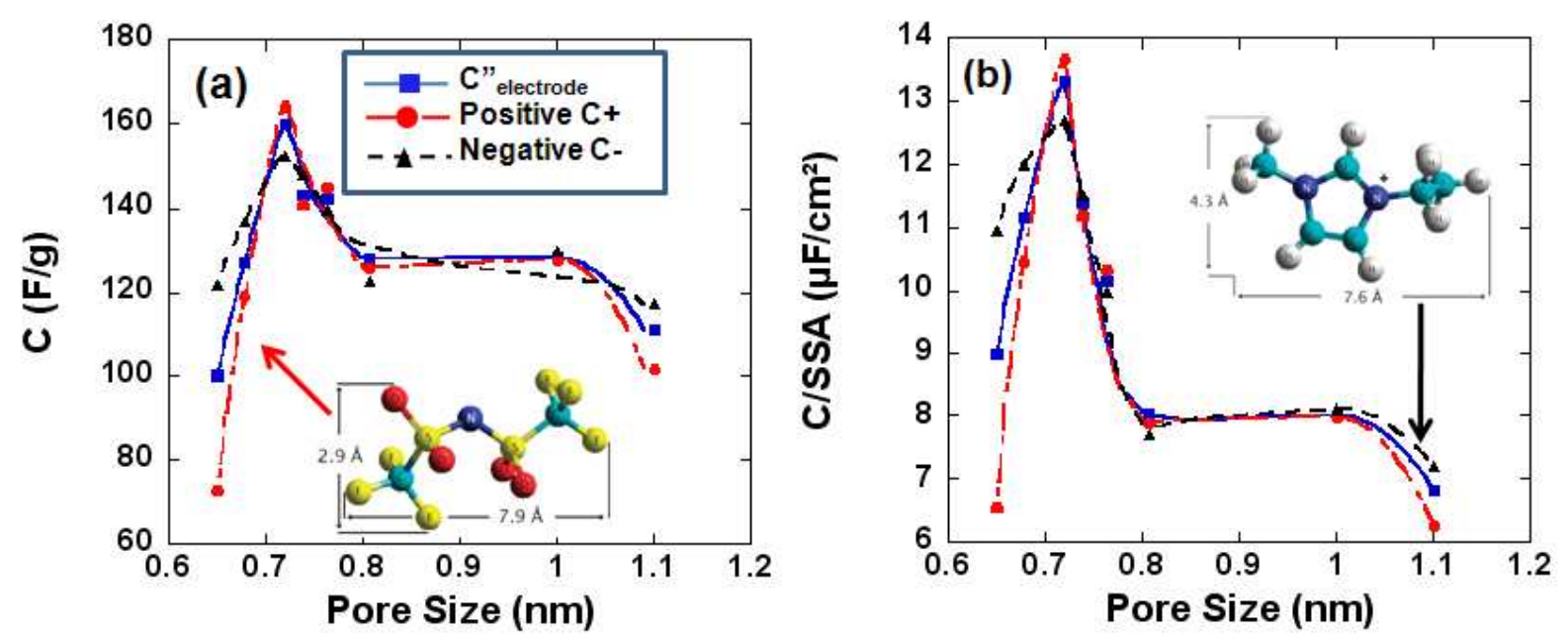

Figure 4: 
Figure 1: Change of the normalized capacitance vs the carbon pore size; normalized capacitance $\left(\mu \mathrm{F} . \mathrm{cm}^{-2}\right)$ was obtained by dividing the gravimetric capacitance by the SSA; from (30).

Figure 2a: Nyquist plot of supercapacitor cells assembled with CDCs with various pore size in $1.5 \mathrm{M} \mathrm{NEt}_{4} \mathrm{BF}_{4}$ in $\mathrm{AN}$ electrolyte. Frequency range: $10 \mathrm{kHz}-10 \mathrm{mHz}$; bias voltage: $0 \mathrm{~V}$.

Figure 2b: Capacitance change vs current density for laboratory cells assembled with CDCs with various pore size.

Figure 3: Cyclic Voltammetries (CVs) of four CDC samples with various pore size $(0.68-1$ $\mathrm{nm}$ ) recorded at $100 \mathrm{mV} . \mathrm{s}^{-1}$ in $1.5 \mathrm{M} \mathrm{NEt}_{4} \mathrm{BF}_{4}$ in $\mathrm{AN}$ electrolyte between $-1.3 \mathrm{~V} / \mathrm{Ref}$. and +1 V/Ref. (Reference electrode is a silver wire); from (35).

Figure 4: Change of the gravimetric capacitance (a) and normalized capacitance (b) vs the carbon pore size for the cell, the positive and the negative electrodes in EMI,TFSI neat electrolyte at $60^{\circ} \mathrm{C}$. Calculated capacitance C" ${ }^{\prime}$ electrode refers to electrode specific capacitance calculated from the overall cell (EDLC) capacitance measured in two-electrode configuration. Capacitance were calculated from galvanostatic charge discharge plots at $10 \mathrm{~mA} . \mathrm{cm}^{-2}$; from (38). 